\title{
Parameter estimation of soil hydraulic and thermal property functions for unsaturated porous media using the HYDRUS-2D code
}

\author{
Mohammad Nakhaei ${ }^{1}$, Jiř́ Šimůnek ${ }^{2 *}$ \\ ${ }^{1}$ Faculty of Geological Sciences, Kharazmi University, No.49, Mofateh Ave., Tehran, Iran. Tel.: +1-951-750-3157, \\ E-mail: nakhaei@khu.ac.ir \\ ${ }^{2}$ Department of Environmental Sciences, University of California, Riverside, USA. \\ *Corresponding author. Tel.: +1-951-827-7854. E-mail: Jiri.Simunek@ucr.edu
}

\begin{abstract}
Knowledge of soil hydraulic and thermal properties is essential for studies involving the combined effects of soil temperature and water input on water flow and redistribution processes under field conditions. The objective of this study was to estimate the parameters characterizing these properties from a transient water flow and heat transport field experiment. Real-time sensors built by the authors were used to monitor soil temperatures at depths of 40, 80, 120, and $160 \mathrm{~cm}$ during a 10-hour long ring infiltration experiment. Water temperatures and cumulative infiltration from a single infiltration ring were monitored simultaneously. The soil hydraulic parameters (the saturated water content $\theta_{s}$, empirical shape parameters $\alpha$ and $n$, and the saturated hydraulic conductivity $K_{s}$ ) and soil thermal conductivity parameters (coefficients $b_{1}, b_{2}$, and $b_{3}$ in the thermal conductivity function) were estimated from cumulative infiltration and temperature measurements by inversely solving a two-dimensional water flow and heat transport using HYDRUS-2D. Three scenarios with a different, sequentially decreasing number of optimized parameters were considered. In scenario 1 , seven parameters $\left(\theta_{s}, K_{s}, \alpha, n, b_{1}, b_{2}\right.$, and $\left.b_{3}\right)$ were included in the inverse problem. The results indicated that this scenario does not provide a unique solution. In scenario 2 , six parameters $\left(K_{s}, \alpha, n, b_{1}, b_{2}\right.$, and $\left.b_{3}\right)$ were included in the inverse problem. The results showed that this scenario also results in a non-unique solution. Only scenario 3 , in which five parameters $(\alpha$, $n, b_{1}, b_{2}$, and $b_{3}$ ) were included in the inverse problem, provided a unique solution. The simulated soil temperatures and cumulative infiltration during the ring infiltration experiment compared reasonably well with their corresponding observed values.
\end{abstract}

Keywords: Infiltration; Heat transport; Parameter Estimation; Richards' equation; HYDRUS-2D.

\section{INTRODUCTION}

The importance of the unsaturated zone as an integral part of the hydrological cycle has long been recognized. The vadose zone plays an important role in many aspects of hydrology, including infiltration, soil moisture storage, evaporation, plant water uptake, groundwater recharge, runoff, and erosion. Simultaneous movement of water and heat in the vadose zone of arid and/or semi-arid regions is of great interest in evaluating water and energy balance of subsurface environments in both agricultural and engineering applications (e.g. Saito et al., 2006). Although it is widely recognized that the movement of water and heat is closely coupled and affect each other (e.g. Nassar and Horton, 1992; Sakai et al., 2009), especially under arid conditions, their mutual interactions are rarely considered in practical applications.

Unsaturated water flow through a porous medium is generally described using the Richards equation. The solution of this equation requires knowledge of soil hydraulic functions, that is, the retention curve, $\theta(h)$, and the hydraulic conductivity function, $K(h)$. Currently there are many laboratory and field methods to determine these nonlinear functions (e.g. Dirksen, 1991; Klute, 1986). The methods with minimum soil disturbance, lowest time requirements, and lowest cost are preferred. Most direct methods require restrictive initial and boundary conditions, which make measurements time consuming and expensive. Direct methods for determining the water retention curve involve equilibrating soil at certain pressure heads or simultaneous measurements of water contents and pressure heads during infiltration or drainage (e.g. Dane and Topp, 2002; Dirksen, 2000).
When the inverse modeling approach is used, the unknown hydraulic parameters are estimated by minimizing deviations between observed variables and model-predicted output for transient flow experiments (e.g. Kool and Parker, 1987; Kool et al., 1987). Collected transient flow data can be inversely analyzed using either analytical or numerical models (e.g. Šimůnek and van Genuchten, 1996; Šimůnek et al., 1998). For the inverse problem solution, we encounter the question: under which circumstances is the inverse problem well posed, utilizing the concepts of identifiability, uniqueness, and stability? It has been shown in the literature, that it may be possible to decrease nonuniqueness of optimized parameters by simultaneously considering multiple processes (e.g. Hopmans et al., 2002; Inoue et al., 2000; Mortensen et al., 2006; Šimůnek et al., 2002). Inoue et al. (2000) and Šimůnek et al. (2002) showed that by simultaneously analyzing data involving both water flow and solute transport variables, they could significantly decrease the uncertainty in the optimized parameters. Similar conclusions were drawn by Hopmans et al. (2002) and Mortensen et al. (2006) who simultaneously analyzed data involving both water flow and heat transport variables.

Analysis of water infiltration experimental data has become a widely used practice for obtaining soil hydraulic properties. The infiltration rate and its variation with time depends upon the initial water content, as well as on the texture, structure, and uniformity (or layering sequence) of the soil profile (Reynolds et al., 2002a, b). The single-ring infiltrometer is often used for measuring cumulative infiltration, from which the infiltration rate, and field-saturated hydraulic conductivity $\left(K_{s}\right)$ are then derived. The infiltration rate is initially large and decreases with time until a near steady-state (gravity-induced) value is at- 
tained. Factors that affect the infiltration rate have been divided into categories of soil factors, surface properties, management factors, and natural properties. Soil factors encompass soil particle size, morphological, chemical, and soil water properties. Surface factors are those that affect the movement of water through the air-soil interface such as soil crust. These factors should be taken into account when parameterizing the infiltration model.

Considerable attention was given in the past to the estimation of soil hydraulic properties from ponded or tension infiltration experiments (e.g. Bohne et al., 1992; Russo et al., 1991; Šimůnek and van Genuchten, 1996). Russo et al. (1991) and Šimůnek and van Genuchten (1996) reported that the cumulative infiltration curve of ponded and tension infiltration experiments, respectively, does not provide enough information to obtain a unique set of optimized parameters, and that some additional information is needed in order to obtain unique solutions for a large number of parameters. Such additional information could include water contents and/or pressure heads (e.g. Šimůnek and van Genuchten, 1996), solute concentrations (e.g. Inoue et al., 2000), or temperatures (e.g. Mortensen et al., 2006) measured at a certain depth under the soil surface.

In the past, relatively few studies have systematically evaluated the simultaneous estimation of soil hydraulic and heat transfer parameters, and therefore the effect of heat transport on water flow has often been neglected. The coupled movement of water and heat in the subsurface is implemented in the HYDRUS codes (Šimůnek et al., 2006, 2008). The HYDRUS-1D and HYDRUS-2D programs numerically solve the Richards equation for saturated-unsaturated water flow and the convection-conduction equation for heat transport in one and two dimensions, respectively. The heat transport equation involves terms accounting for the transport due to conduction and convection with flowing water. The program may be used to analyze water and heat movement in unsaturated, partiallysaturated, or fully-saturated porous media. Examples in which soil thermal parameters have been estimated using HYDRUS include studies by Hopmans et al. (2002), Mortensen et al. (2006), Saito et al. (2007), and Sakai et al. (2009).

While it was shown by Russo et al. (1991) and several others (e.g. Šimůnek and van Genuchten, 1996) that cumulative infiltration data alone cannot be used to estimate more than two soil hydraulic parameters due to problems with parameter uniqueness, the combined use of water flow and heat transport data in the objective function of the inverse problem may significantly reduce the uncertainty of the optimized parameters and enhance their identifiability. The first objective of this study was thus to collect data during the ring infiltration experiment and to simultaneously measure cumulative infiltration and soil temperatures in several depths under the center of the infiltration ring. The second objective was to analyze the water flow and heat transport data using the parameter estimation approach in HYDRUS-2D to simultaneously estimate soil hydraulic and heat transport parameters.

\section{MATERIAL AND METHODS Study area}

The study area is located on the campus of Kharazmi University in the city of Karaj, Alborz province, 48 kilometers outside Tehran, Iran. The altitude is $1,297 \mathrm{~m}$ above sea level, and the annual average precipitation is approximately $300 \mathrm{~mm}$. The annual average temperature is about $16^{\circ} \mathrm{C}$. The geology is dominated by the Karaj tuff formations. Soils developed from this bedrock are sandy loams with a low content of clay. The vegetation cover is sparse.

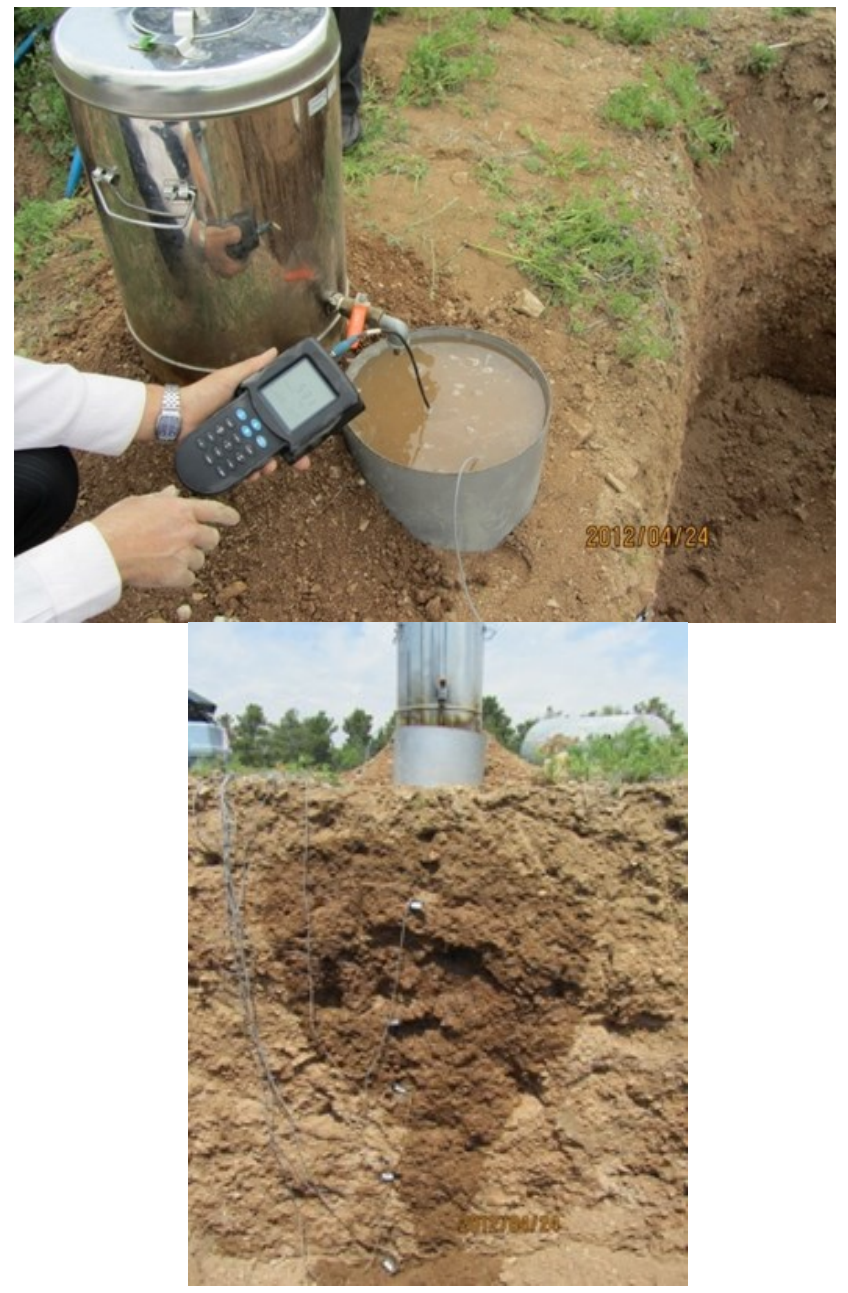

Fig. 1. Photo of the experiment and locations of thermal sensors.

\section{Soil sampling}

To determine the saturated hydraulic conductivity, $K_{s}$, as well as the soil bulk density, $\rho$, the initial water content, and the grain-size distribution curve (soil texture), two undisturbed soil samples were collected using an auger from a depth of $1.0 \mathrm{~m}$, about $50 \mathrm{~cm}$ away from the center of the infiltration ring. The soil samples were analyzed in the sedimentology laboratory of Kharazmi University. Using the sieve analysis, the soil texture was determined to be a silt loam (based on the USDA textural triangle; e.g. Radcliffe and Šimůnek, 2010) with a low content of clay ( $40 \%$ sand, $55 \%$ silt, and $5 \%$ clay). The soil could also be classified as "Sandy Silt" according to the textural classification scheme for siliciclastics soil, modified from Shepard (1954), which subdivides the textural triangle into sandy clay, silty clay, sandy silt, clayey silt, clayey sand, and silty sand classes. The measured soil bulk density and the saturated water content were $1.24 \mathrm{~g} / \mathrm{cm}^{3}$ and 0.43 , respectively. Bulk density, soil water content, and soil texture were measured using standard methods described by Klute (1986).

\section{Single ring infiltration experiment}

We used the following procedure to conduct the single-ring infiltration experiment in the field. First, we cleared the sam- 
pling area of surface residues that could impede insertion of the ring. Second, using a sledge hammer and block of wood, we inserted the single $40-\mathrm{cm}$ diameter infiltration ring (Fig. 1) down to a depth of $3 \mathrm{~cm}$, keeping the ring sides vertical and the soil disturbance to a minimum. Third, we consolidated the soil on the inside of the ring and sealed the space outside of the ring using bentonite to prevent unwanted seepage. Finally, we instrumented the soil profile with 4 thermal sensors at depths of $40,80,120$, and $160 \mathrm{~cm}$ (Fig. 2). Thermal sensors were installed from a trench wall, about $50 \mathrm{~cm}$ aside from the center of the ring, by horizontally drilling small diameter holes below the center of the ring. Drilled holes were filled with a wet fine silty soil to guarantee a complete contact between soil and sensors. The performance of the sensors was successfully compared against the HACH SensION-156 Portable Multiparameter, a 5pin $(\mathrm{pH} / \mathrm{mV} /$ temperature/conductivity/dissolved oxygen) probe. The measurement period was from 8.00 to 18.00 hours on April $4^{\text {th }}, 2012$. Air temperature was $20^{\circ} \mathrm{C}$ and initial soil temperatures at observation depths were $17.5^{\circ} \mathrm{C}$. The temperature of the infiltration water was $61^{\circ} \mathrm{C}$ during the entire experiment. In our calculations we assumed that the effect of air temperature variations during the experiment was negligible. The final steadystate infiltration rate was also measured and subsequently used for calculating the saturated hydraulic conductivity of the soil using the Wooding (1968) equation (cited from Radcliffe and Šimůnek, 2010, p. 106).
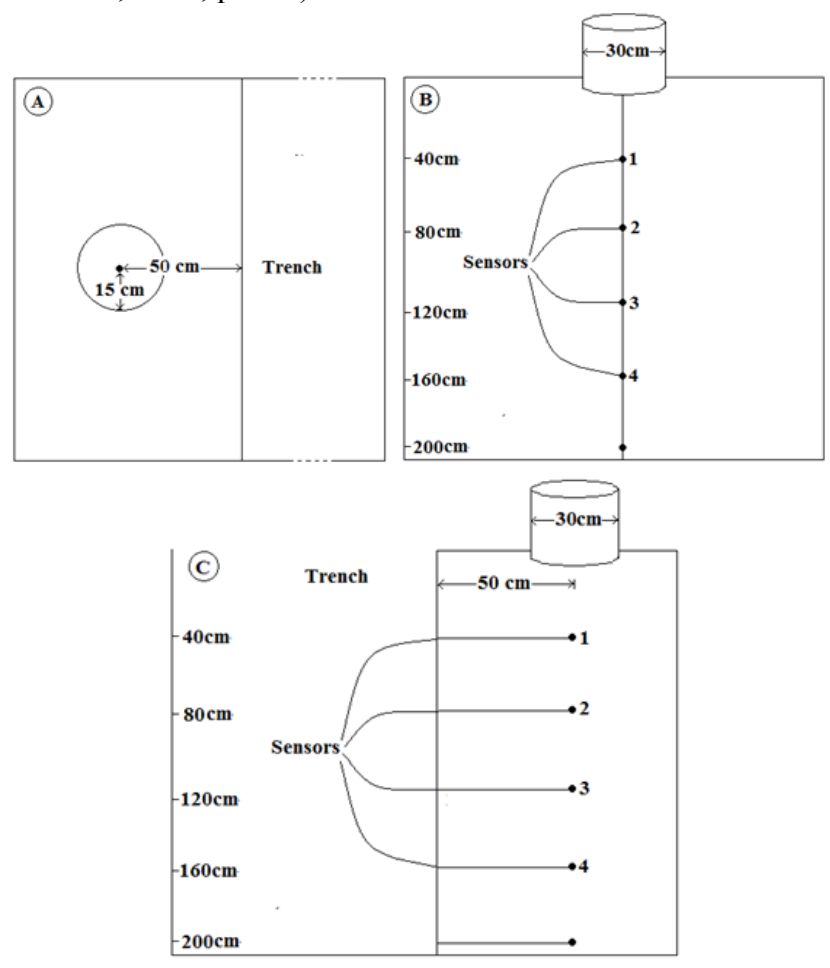

Fig. 2. Schematic of a single infiltration ring experiment. A - plane view, B - Frontal view, C-Lateral view.

\section{The numerical model}

The HYDRUS-2D software package (version 1.12 of HYDRUS (2D/3D); Šimůnek et al., 2006) was used to model the soil water dynamics and heat transport assuming an axisymmetric transport domain.

\section{Soil hydraulic properties}

HYDRUS implements the soil hydraulic functions of van Genuchten (1980), who used the statistical pore-size distribution model of Mualem (1976) to obtain a predictive equation for the unsaturated hydraulic conductivity function in terms of soil water retention parameters. The expressions of van Genuchten (1980) are given by Eq. (1) and Eq. (2):

$S_{e}(h)=\frac{\theta-\theta_{r}}{\theta_{s}-\theta_{r}}=\left\{\begin{array}{cc}\frac{1}{\left[1+|\alpha h|^{n}\right]^{m}} & h<0 \\ 1 & h \geq 0\end{array}\right.$,

$$
K(h)=K_{s} S_{e}^{l}\left[1-\left(1-S_{e}^{1 / m}\right)^{m}\right]^{2} \quad,
$$

in which $\theta$ is the volumetric water content [-], $\theta_{\mathrm{r}}$ and $\theta_{s}$ denote the residual and saturated water content [-], respectively; $S_{e}$ is the effective fluid saturation [-], $K_{s}$ is the saturated hydraulic conductivity $\left[\mathrm{LT}^{-1}\right], \alpha\left[\mathrm{L}^{-1}\right], n[-]$, and $m(=1-1 / n)[-]$ are empirical shape parameters, and $l$ is a pore-connectivity parameter assumed to be 0.5 [-] (Mualem, 1976).

\section{Temperature dependence of the soil hydraulic functions}

A scaling technique similar to one used to describe spatial variability of soil hydraulic properties (Vogel et al., 1991) is used in HYDRUS to express the temperature dependence of the soil hydraulic functions. Based on the capillary theory that assumes that the influence of temperature on the soil water pressure head can be quantitatively predicted from the influence of temperature on the surface tension, Philip and de Vries (1957) derived the following equation:

$$
\frac{d h}{d T}=\frac{h}{\sigma} \frac{d \sigma}{d T},
$$

where $T$ is temperature $[\mathrm{K}]$ and $\sigma$ is the surface tension at the air-water interface $\left[\mathrm{MT}^{-2}\right]$. From (3) it follows that:

$$
h_{T}=\frac{\sigma_{T}}{\sigma_{r e f}} h_{r e f}=\alpha_{h}^{*} h_{r e f},
$$

where $h_{T}$ and $h_{r e f}\left(\sigma_{T}\right.$ and $\left.\sigma_{r e f}\right)$ are pressure heads (surface tensions) at temperature $T$ and reference temperature $T_{\text {ref }}$, respectively, and $\alpha_{h}{ }^{*}$ is the temperature scaling factor for the pressure head. Following Constantz (1982), the temperature dependence of the hydraulic conductivity can be expressed as follows:

$$
K_{T}(\theta)=\frac{\mu_{r e f}}{\mu_{T}} \frac{\rho_{T}}{\rho_{r e f}} K_{r e f}(\theta)=\alpha_{K}^{*} K_{r e f}(\theta),
$$

where $K_{\text {ref }}$ and $K_{T}$ denote hydraulic conductivities at the reference temperature $T_{\text {ref }}$ and soil temperature $T$, respectively, $\mu_{\text {ref }}$ and $\mu_{T}\left(\rho_{r e f}\right.$ and $\left.\rho_{T}\right)$ represent the dynamic viscosity $\left[\mathrm{ML}^{-1} \mathrm{~T}^{-1}\right]$ (density of soil water $\left[\mathrm{ML}^{-3}\right]$ ) at temperatures $T_{\text {ref }}$ and $T$, respectively, and $\alpha_{K}{ }^{*}$ is the temperature scaling factor for the hydraulic conductivity. 


\section{Heat transport}

Neglecting the effects of water vapor diffusion, two- and three-dimensional heat transport can be described as (Sophocleous, 1979):

$$
C(\theta) \frac{\partial T}{\partial t}=\frac{\partial}{\partial x_{i}}\left(\lambda_{i j}(\theta) \frac{\partial T}{\partial x_{j}}\right)-C_{w} q_{i} \frac{\partial T}{\partial x_{i}}
$$

where $\lambda_{i j}(\theta)$ is the apparent thermal conductivity of the soil [MLT ${ }^{-3} \mathrm{~K}^{-1}$ ] (e.g. $\mathrm{Wm}^{-1} \mathrm{~K}^{-1}$ ), and $C(\theta)$ and $C_{w}$ are the volumetric heat capacities $\left[\mathrm{ML}^{-1} \mathrm{~T}^{-2} \mathrm{~K}^{-1}\right]$ (e.g. $\mathrm{Jm}^{-3} \mathrm{~K}^{-1}$ ) of the porous medium and the liquid phase, respectively. Volumetric heat capacity is defined as the product of the bulk density and the gravimetric heat capacity. The first term on the right-hand side of (6) represents heat flow due to conduction, and the second term accounts for heat being transported by flowing water. We do not consider the transfer of latent heat by vapor movement. According to de Vries (1963), the volumetric heat capacity can be expressed as:

$$
C(\theta)=C_{n} \varepsilon_{n}+C_{o} \varepsilon_{o}+C_{w} \varepsilon_{w}+C_{g} \varepsilon_{g},
$$

where $\varepsilon$ refers to a volumetric fraction $\left[\mathrm{L}^{3} \mathrm{~L}^{-3}\right]$, and subscripts $n$, $o, g$, and $w$ represent solid phase, organic matter, gas phase and liquid phase, respectively.

\section{Apparent thermal conductivity coefficient}

The apparent thermal conductivity, $\lambda_{i j}(\theta)$, combines the thermal conductivity $\lambda_{0}(\theta)$ of the porous medium (solid plus water) in the absence of flow, and the macro-dispersivity, which is assumed to be a linear function of the velocity (de Marsily, 1986). In analogy with the dispersion coefficient for solute transport, the apparent thermal conductivity $\lambda_{i j}(\theta)$ is given by (Šimůnek and Suarez, 1993):

$$
\lambda_{i j}(\theta)=\lambda_{T} C_{w}|q| \delta_{i j}+\left(\lambda_{L}-\lambda_{T}\right) C_{w} \frac{q_{j} q_{i}}{|q|}+\lambda_{0}(\theta) \delta_{i j},
$$

where $q$ is the absolute value of the Darcian fluid flux density $\left[\mathrm{LT}^{-1}\right], \delta_{i j}$ is the Kronecker delta function, and $\lambda_{L}$ and $\lambda_{T}$ are the longitudinal and transverse thermal dispersivities [L], respectively. The volumetric heat capacity of the liquid phase $C_{w}$ is included in the definition of the thermal conductivity in order to have the dimensions of the thermal dispersivities in length units (de Marsily, 1986). The thermal conductivity, $\lambda_{0}(\theta)$, accounts for the tortuosity of the porous medium, and is described with the simple equation (Chung and Horton, 1987):

$$
\lambda_{0}(\theta)=b_{1}+b_{2} \theta+b_{3} \theta^{0.5}
$$

where $b_{1}, b_{2}$ and $b_{3}$ are empirical parameters $\left[\mathrm{MLT}^{-3} \mathrm{~K}^{-1}\right]$ (e.g. $\mathrm{Wm}^{-1} \mathrm{~K}^{-1}$ ).

\section{Numerical model \\ Transport domain}

The axisymmetrical transport domain was $100 \mathrm{~cm}$ wide and $200 \mathrm{~cm}$ deep. The domain was discretized into 441 nodes and 400 triangular finite elements. Simulations were carried out over a period of 10 hours.

\section{Initial and boundary conditions}

The initial water content considered in the simulation $(0.041$ $\mathrm{cm}^{3} / \mathrm{cm}^{3}$ ) was measured in the field. A soil profile temperature of $17.5^{\circ} \mathrm{C}$, as measured in the field, was used as the initial condition for heat transport. All sides of the flow region were considered to be impervious, except for a small portion around the origin at the ponded surface inside the ring infiltrometer where a constant water content was imposed, and for the bottom of the soil profile where a free drainage condition was imposed. The volumetric water content of 0.43 was used as the water flow boundary condition under the single infiltration ring. A firsttype heat transport boundary condition was used for nodes under the single infiltration ring with a constant temperature of $61^{\circ} \mathrm{C}$, representing hot water infiltrating into the soil profile. A third-type heat transport boundary condition was invoked at the bottom of the soil profile. No flux boundary conditions were used for both water flow and heat transport along all other boundary nodes.

\section{Inverse solution}

The Levenberg-Marquardt optimization algorithm (Marquardt, 1963), in combination with the HYDRUS-2D numerical code (Šimůnek et al., 2006), was used to inversely estimate unsaturated soil hydraulic and heat transport parameters from the transient cumulative water flux from a single-ring infiltration experiment and soil temperatures measured at multiple depths. An inverse problem requires the same type of information as a forward problem. It also requires initial estimates of optimized parameters, positions of observation points, and measured data with corresponding measurement times and weighing factors.

A summary of various approaches that are routinely used in inverse modeling is provided by Hopmans and Šimůnek (1999) and Vrugt et al. (2008). Optimized hydraulic and thermal parameters are determined by systematically minimizing the differences between observed and simulated state variables (e.g. cumulative infiltration and temperatures). The sum of squares of these differences is expressed using an objective function, $\phi$, which may be defined as:

$\phi(\beta, y)=\sum_{j=1}^{j=m_{y}} v_{j} \sum_{i=1}^{i=n_{j}} w_{i, j}\left[y_{j}^{*}\left(z, t_{i}\right)-y_{j}\left(z, t_{i}, \beta\right)\right]^{2}$,

where the right-hand side represents the residuals between space-time variables that are measured $\left(y_{j}^{*}\right)$ and modelpredicted $\left(y_{j}\right)$ using the soil hydraulic and thermal parameters of the optimized parameter vector, $\beta$. The first summation sums the residual for all measurement types $m_{y}$ (e.g. cumulative infiltration and temperatures), whereas the variable $n_{j}$ in the second summation denotes the number of measurements for a certain measurement type $\mathrm{j}$. In this paper, $y_{j}{ }^{*}$ represents cumulative infiltration from a single ring and temperature measurements at 4 different depths of the soil profile. Assuming that the measurement errors within a measurement type are independent and uncorrelated, the weighting factor values for $v_{j}$ can be selected such that data types are weighted equally using the reciprocal of the measurement variance of measurement type $j$ (Clausnitzer and Hopmans, 1995).

The Levenberg-Marquardt method, which is a gradientbased, nonlinear optimization technique, was used to minimize the objective function (10). However, inverse problems are often ill-posed, which results in optimized parameters being 
unidentifiable and/or non-unique, producing divergent, unstable results (Hopmans and Šimůnek, 1999). Because it is not $a$ priori clear whether the inverse problem is sufficiently wellposed to allow parameter optimization when using cumulative infiltration from a single-ring infiltration experiment and soil temperatures measured at multiple depths, the parameter optimization procedure was repeated many times with different initial estimates of the optimized parameters. The initial estimates of flow parameters (soil hydraulic parameters) were taken from the ROSETTA program (Schaap et al., 2001).

The behavior of the inverse problem can be evaluated by plotting the value of the objective function, $\phi$, against a pair of optimized parameters to obtain the so-called response surfaces. Each response surface is obtained by solving the flow and transport equations, with appropriate initial and boundary conditions, for many possible combinations of a selected pair of parameter values within a predetermined range, while keeping the other parameters constant. Since only two parameters appear within a single response surface analysis, the behavior of $\phi$ in the various parameter planes is only an indication of the uniqueness of the solution in these planes and not in the full parameter space. For example, other local minima may exist elsewhere in the full parameter space but not appear in the selected cross-sectional planes (Šimůnek and van Genuchten, 1996).

The validity of estimated parameters can be assessed by an uncertainty analysis, which yields confidence intervals for the estimated parameters. This analysis assumes that uncertainty is caused by measurement errors only, that is, that the model error is zero, and that the inverse solution has converged to the global minimum. The uncertainty analysis provides a means to compare confidence intervals among parameters; thereby indicating which parameters should be measured or estimated independently.

We carried out three different scenarios with a different number of optimized parameters to test the uniqueness of the inverse solution. In Scenario 1, we considered four parameters of the van Genuchten model $\left(\theta_{s}, \alpha, n\right.$, and $\left.K_{s}\right)$ and three parameters of the thermal conductivity function $\left(b_{1}, b_{2}\right.$, and $\left.b_{3}\right)$ as unknown parameters in the inverse solution. In Scenario 2, we considered three parameters of the van Genuchten model $(\alpha, n$, and $\left.K_{s}\right)$ and three thermal conductivity parameters $\left(b_{1}, b_{2}\right.$, and $b_{3}$ ) as unknown parameters. Finally, in Scenario 3, we considered only the van Genuchten-Mualem parameters $\alpha$ and $n$, and the empirical parameters $b_{1}, b_{2}$, and $b_{3}$ of the thermal conductivity function as unknowns. The saturated water content, $\theta_{s}$, and the saturated hydraulic conductivity, $K_{s}$, determined using independent measurements, were considered as known parameters in both Scenario 2 and 3. The tortuosity parameter $l$ was set in all scenarios to a fixed value of 0.5 (Mualem, 1976). The residual water content $\theta_{s}$ was fixed to a value of 0.001 .

\section{RESULTS AND DISCUSSION}

The steady-state infiltration rate from the ring was 0.00166 $\mathrm{cm} / \mathrm{s}$. Using the macroscopic capillary length of $8.3 \mathrm{~cm}$ for the loamy soil (Radcliffe and Šimůnek, 2010), we calculated the saturated hydraulic conductivity of $0.0011 \mathrm{~cm} / \mathrm{s}$ using Wooding's analytical solution (Wooding, 1968) and used this value as an initial estimate in the inverse solution. Measured cumulative infiltration and soil temperatures measured at four observation depths were then used to optimize selected soil hydraulic and heat transport parameters of a silt loam soil profile.
Table 1 shows the values of soil hydraulic and thermal parameters that were used in all simulations when they were not optimized. Table 2 then shows the initial estimate and final values of the optimized soil hydraulic and thermal parameters, $R^{2}$, and $S S Q$ for different optimization runs (different scenario). In Scenario 1, since the optimized parameters were often very different in different optimization runs with different initial values of optimized parameters, the inverse problem was clearly not well posed. In Scenario 2, although the inverse solutions showed less variation in optimized parameters than in Scenario 1 , the inverse solution was still non-unique. Only in Scenario 3, the inverse solution for many different runs converged to the same solution, indicating a unique solution. Table 2 lists $R^{2}$ values for the best optimization runs that quantify the accuracy of regression. As all correlation values are very high, their magnitude is of little value for testing the model's adequacy.

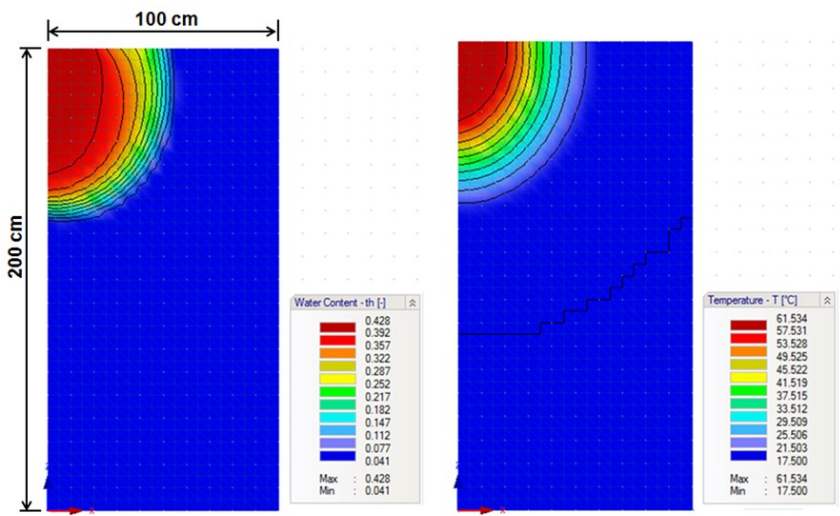

Fig. 3. Final simulated water contents (left) and temperatures (right) in the soil profile for Scenario 3.
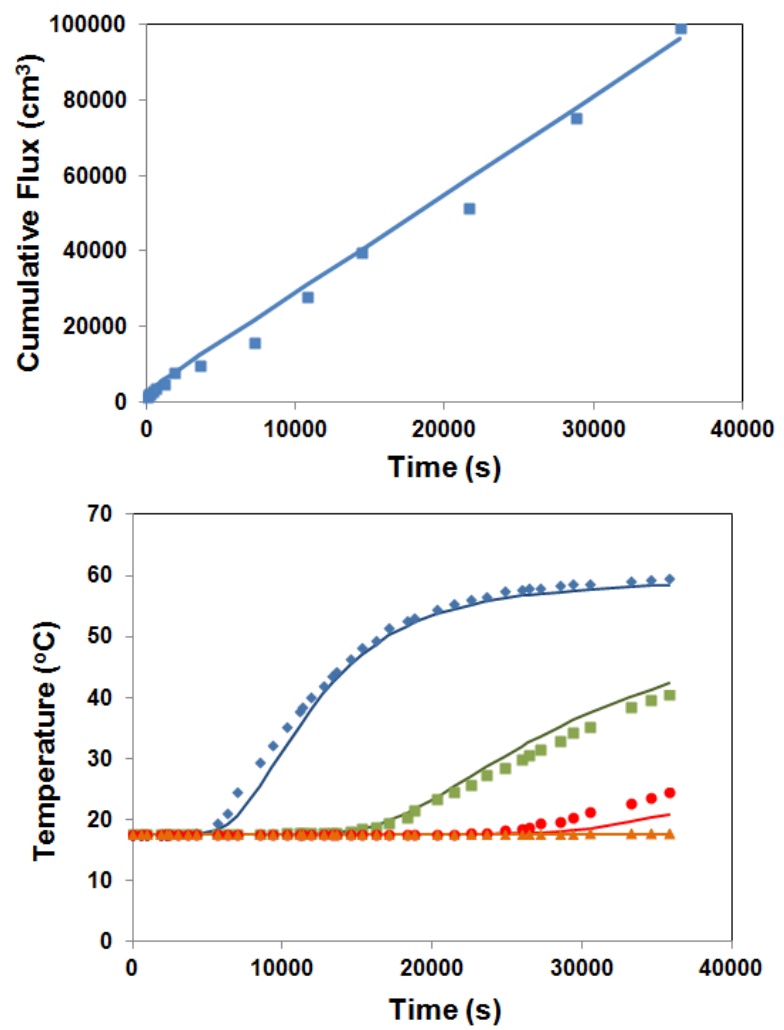

Fig. 4. Simulated and observed cumulative fluxes (top) and temperatures at four depths (bottom) (blue $-40 \mathrm{~cm}$, green $-80 \mathrm{~cm}$, red $-120 \mathrm{~cm}$, beige $-160 \mathrm{~cm})$. 
Fig. 3 shows an example of the output simulated by the HYDRUS-2D model for Scenario 3. It shows the final spatial distribution of water contents and temperatures in the soil profile. Fig. 3 shows that at the end of the simulation the moisture front reaches the horizontal distance of about $50 \mathrm{~cm}$ from the centre of the ring, which is the distance of the trench from which temperature sensors were installed. Notice that the moisture front is also visible in the trench in Fig. 1. This indicates that the trench starts affecting the flow field only at the very end of the experiment and that the use of axisymmetrical domain in the analysis is acceptable. Fig. 4 compares simulated and measured cumulative infiltrations and simulated and measured temperatures in the soil profile at depths of $40,80,120$, and $160 \mathrm{~cm}$. Both temperatures and cumulative infiltrations optimized with the model fitted the measured data well. Also, the coefficient of determination $\left(R^{2}\right)$ (Table 2) indicated a good fit. $R^{2}$ for regression of predicted versus observed values is equal to 0.995 .

Table 1. Values of soil hydraulic and thermal parameters that were not optimized.

\begin{tabular}{|l|c|c|}
\hline Parameters (unit) & Parameter name & value \\
\hline$\theta_{r}\left(\mathrm{~cm}^{3} / \mathrm{cm}^{3}\right)$ & Residual moisture content & 0.001 \\
\hline$\theta_{s}\left(\mathrm{~cm}^{3} / \mathrm{cm}^{3}\right)$ & Saturated moisture content & 0.430 \\
\hline$K_{s}(\mathrm{~cm} / \mathrm{s})$ & Saturated hydraulic conductivity & 0.0011 \\
\hline$l(-)$ & Pore connectivity factor & 0.500 \\
\hline$\theta_{n}[-]$ & Solid fraction & 0.600 \\
\hline$\theta_{o}[-]$ & Organic matter fraction & 0.001 \\
\hline$\lambda_{L}[\mathrm{~cm}]$ & Thermal dispersivity longitudinal & 2.000 \\
\hline$\lambda_{T}\left[\mathrm{~cm}^{3}\right.$ & Thermal dispersivity transverse & 0.200 \\
\hline$C_{n}\left[\mathrm{~J} / \mathrm{M}^{3} / \mathrm{K}\right]$ & Heat capacity of the solid phase & 1920000 \\
\hline$C_{o}\left[\mathrm{~J} / \mathrm{M}^{3} / \mathrm{K}\right]$ & Heat capacity of the organic matter & 2510000 \\
\hline$C_{w}\left[\mathrm{~J} / \mathrm{M}^{3} / \mathrm{K}\right]$ & Heat capacity of water & 4180000 \\
\hline
\end{tabular}

Fig. 5 shows a comparison of the optimized thermal conductivity function $\lambda_{0}(\theta)$ for our silt loam soil with those for the three main textural classes of clay, loam, and sand (Chung and Horton, 1987). The results indicate that the optimized thermal conductivity function is relative similar to (between) those for loam and clay.

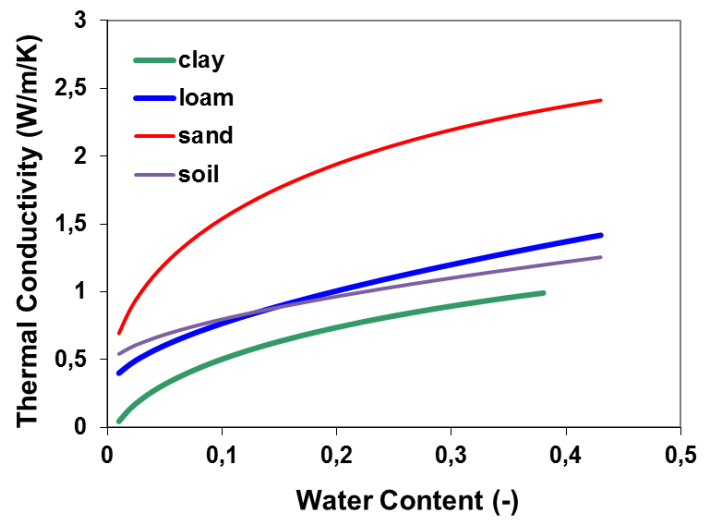

Fig. 5. Comparison of the optimized thermal conductivity function $\lambda_{0}(\theta)$ (denoted as "soil") with those for main textural classes clay, loam, and sand (Chung and Horton, 1987).
Table 3 shows the upper and lower bounds (95\% confidence interval) of the optimized parameters for different optimization scenarios and the final optimized soil hydraulic and heat transport parameters obtained in Scenario 3. Confidence intervals for optimized model parameters for a given level of significance were calculated from the variances of the estimated model parameters. As shown in Table 2, the optimized soil hydraulic and heat transport parameters have narrow confidence intervals only when the saturated water content and the saturated hydraulic conductivity are assumed to be known (from independent measurements), and only the $\alpha$ and $n$ parameters of the van Genuchten model are considered to be the unknown soil hydraulic parameters in the inverse problem.
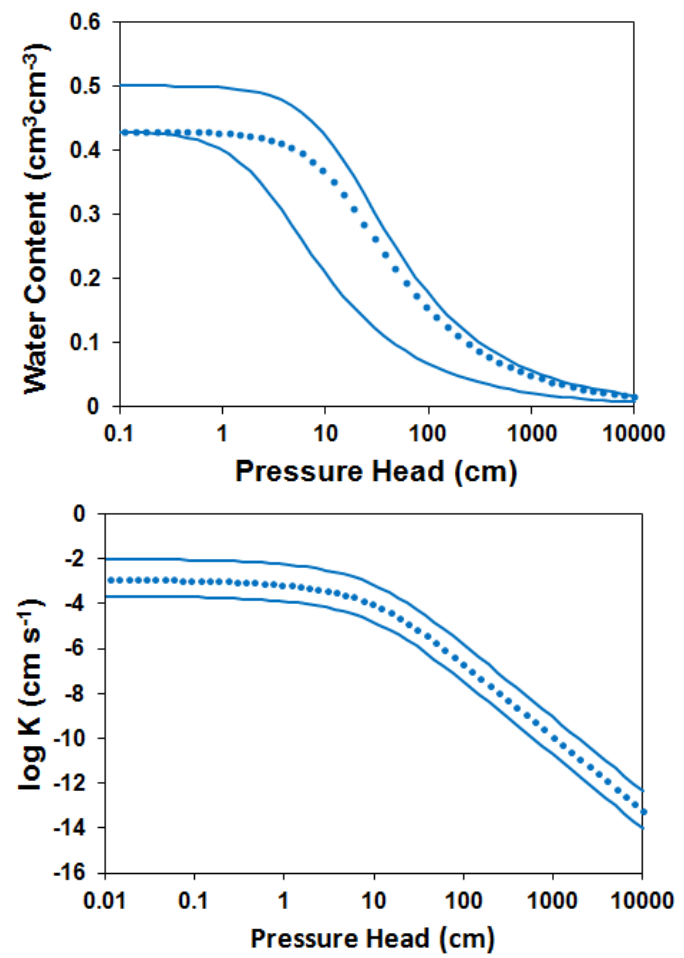

Fig. 6. Uncertainty in optimized $\theta$ (h) (top) and $\log K(\mathrm{~h})(\mathrm{cm} / \mathrm{s})$ (bottom) functions in Scenario 3. Dotted lines represent the optimized functions and solid lines the $95 \%$ confidence intervals.

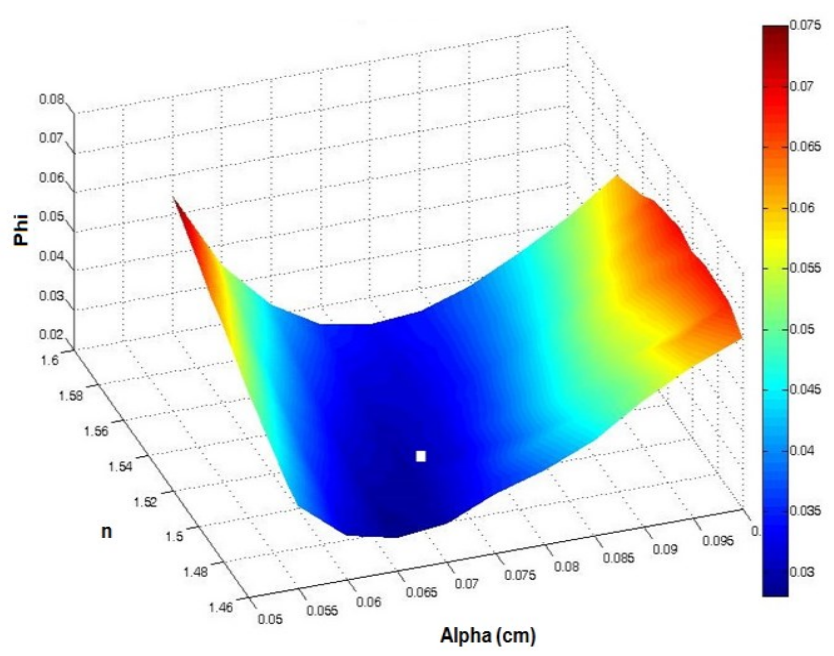

Fig. 7. A response surface in the $\alpha-n$ parameter plane for Scenario 3 . The white square indicates the minimum of the objective function $\phi$ for a final set of parameters (Table 3). 
Table 2. Optimized soil hydraulic and thermal parameters, $R^{2}$, and $S S Q$ for three scenarios (for optimization runs with the lowest value of $S S Q)$.

\begin{tabular}{|c|c|c|c|c|c|c|c|c|c|c|c|c|c|}
\hline \multirow{2}{*}{ 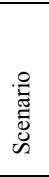 } & \multicolumn{4}{|c|}{$\begin{array}{l}\text { Water flow parameters: } \\
\text { Initial estimates }\end{array}$} & \multicolumn{4}{|c|}{$\begin{array}{l}\text { Water flow parameters: } \\
\text { Optimized values }\end{array}$} & \multicolumn{3}{|c|}{$\begin{array}{l}\text { Heat transport parameters } \\
\text { Optimized value } \\
\left(\mathrm{kg} \mathrm{cm} \mathrm{s}^{-3} \mathrm{~K}^{-1}\right)\end{array}$} & \multirow{2}{*}{$\begin{array}{c}R^{2} \\
-\end{array}$} & \multirow{2}{*}{$\begin{array}{c}\begin{array}{c}\text { Objec } \\
\text { tive } \\
\text { func- } \\
\text { tion }\end{array} \\
S S Q^{*}\end{array}$} \\
\hline & $\theta_{s}$ & $\begin{array}{c}\alpha \\
(1 / \mathrm{cm})\end{array}$ & $n$ & $K_{s}(\mathrm{~cm} / \mathrm{s})$ & $\theta_{s}$ & $\begin{array}{c}\alpha \\
(1 / \mathrm{cm})\end{array}$ & $n$ & $\begin{array}{c}K_{s} \\
(\mathrm{~cm} / \mathrm{s})\end{array}$ & $b_{1}$ & $b_{2}$ & $b_{3}$ & & \\
\hline 1 & 0.43 & 0.035 & 1.5 & 0.00106 & 0.377 & 0.065 & 1.52 & 0.00118 & 24.82 & 67.64 & 96.76 & 0.995 & 0.014 \\
\hline 2 & \# & 0.075 & 2.0 & 0.00132 & \# & 0.075 & 1.51 & 0.00122 & 88.3 & 10.1 & 47.6 & 0.995 & 0.016 \\
\hline 3 & \# & 0.048 & 1.60 & \# & \# & 0.075 & 1.51 & \# & 43.3 & 29.6 & 106.0 & 0.998 & 0.007 \\
\hline
\end{tabular}

*SSQ: Value of the objective function $\Phi$ being minimized during the parameter optimization process.

$R^{2}$ : Regression between observed and fitted values.

\#: Parameter is not included in the parameter optimization process.

Table 3. The upper and lower bounds (95\% confidence interval) of the optimized parameters for three scenarios. The final column gives final parameter values for Scenario 3.

\begin{tabular}{|c|c|c|c|c|c|c|c|}
\hline \multirow[b]{2}{*}{ Parameters } & \multicolumn{2}{|c|}{ Scenario 1} & \multicolumn{2}{|c|}{ Scenario 2} & \multicolumn{2}{|c|}{ Scenario 3} & \multirow{2}{*}{$\begin{array}{l}\text { Final parameter values for } \\
\text { Scenario } 3\end{array}$} \\
\hline & $\begin{array}{l}\text { Lower } \\
\text { bound }\end{array}$ & $\begin{array}{l}\text { Upper } \\
\text { bound }\end{array}$ & Lower bound & $\begin{array}{l}\text { Upper } \\
\text { bound }\end{array}$ & $\begin{array}{l}\text { Lower } \\
\text { bound }\end{array}$ & Upper bound & \\
\hline$\theta_{s}\left(\mathrm{~cm}^{3} / \mathrm{cm}^{3}\right)$ & 0.216 & 0.501 & $\#$ & $\#$ & \# & $\#$ & 0.43 \\
\hline$K_{s}(\mathrm{~cm} / \mathrm{s})$ & 0.00023 & 0.01039 & 0.00119 & 0.00137 & \# & $\#$ & 0.00132 \\
\hline$\alpha(1 / \mathrm{cm})$ & 0.009 & 0.102 & 0.066 & 0.084 & 0.072 & 0.078 & 0.075 \\
\hline$n(-)$ & 1.160 & 2.570 & 1.4 & 1.62 & 1.5 & 1.6 & 1.51 \\
\hline$b_{1}\left(\mathrm{~kg} \mathrm{~cm} \mathrm{~s}^{-3} \mathrm{~K}^{-1}\right)$ & 0.071 & 78.90 & 28.7 & 122.1 & 30.3 & 70.1 & 43.3 \\
\hline$b_{2}\left(\mathrm{~kg} \mathrm{~cm} \mathrm{~s}^{-3} \mathrm{~K}^{-1}\right)$ & 0.0364 & 578.2 & 0.24 & 62 & 20.7 & 57.3 & 29.6 \\
\hline$b_{3}\left(\mathrm{~kg} \mathrm{~cm} \mathrm{~s}^{-3} \mathrm{~K}^{-1}\right)$ & 1.295 & 425.7 & 10.6 & 147.1 & 78.5 & 140.3 & 106.0 \\
\hline
\end{tabular}

\#: not included in the parameter optimization.

Uncertainties introduced into the optimized soil hydraulic functions by measurement errors, and other factors discussed above, are shown in Fig. 6. When selecting the best estimates of optimized parameters, we considered their $95 \%$ confidence intervals, the magnitude of objective function and the $R^{2}$. By adjusting the weights of data points related to flow and temperature variables in the objective function, we attempted to give the same weights to both measurement sets. Although not defining weights strictly based on measurement errors makes it difficult to interpret the resulting optimized parameters, their confidence intervals, correlations, and, in general, their relationship with the true parameter values (Bard, 1974), this is a common approach in many applications since the measurement errors are often not known and thus the corresponding weights are then not specified based on probabilistic assumptions. However, weights still need to be selected with caution since an improper selection of weights can influence not only the confidence regions of optimized parameters, but also the location of the minimum of the objective function (Hollenbeck et al, 2000). Even the robustness of the least-squares criterion for the estimation of model parameters has recently been questioned by Finsterle and Najita (1998). They pointed out that the leastsquare criterion causes outliers to strongly influence the final values of optimized parameters. Hence, outliers (e.g. individual data points with large measurement errors, as is often the case with field measurements) can introduce a significant bias in the estimated model parameters. Finsterle and Najita (1998) studied several other more robust estimators with different error distributions that reduce the effect of outliers on the optimized parameters. However, using these estimators in our analysis is beyond the scope of this manuscript.
Finally, Fig. 7 shows a response surface in the $\alpha-n$ parameter plane for Scenario 3. The response surface was calculated on a rectangular grid size of $50 \times 50$. While the $\alpha$ and $n$ parameters have been varied in the intervals of $0.05-0.1$ and $1.46-1.56$, respectively, the values of fixed parameters were $\theta_{r}=0.001$, $\theta_{s}=0.43, K_{s}=0.00132 \mathrm{~cm} / \mathrm{s}, b_{1}=43.3, b_{2}=29.6$, and $b_{3}=106(\mathrm{~kg}$ $\mathrm{cm} \mathrm{s}^{-3} \mathrm{~K}^{-1}$ ). The shape of the response surface indicates that while the $\alpha$ parameter is relatively well defined in this interval, the $n$ parameter is more uncertain, confirming our results reported in Table 2.

\section{CONCLUSIONS}

In this study we used HYDRUS-2D to simulate infiltration of relatively warm water from a single-ring infiltrometer into a silt loam soil profile and to estimate the soil thermal and hydraulics properties by inverse solution from collected experimental data. We showed that the cumulative infiltration and temperatures collected at four sensors at four different depths could provide the required information for simultaneous estimation of the soil thermal and soil hydraulic properties.

The results indicate that measurements of cumulative infiltration and temperature data would not necessarily result in unique and reliable estimates of hydraulic parameters when the number of unknown soil thermal parameters is three and soil hydraulic parameters is more than two. Prior information regarding the optimized parameters or additional measurements are needed for the estimation problem to be well posed. When infiltration data are used as input in the inversion procedure, the inclusion of prior information on measurable parameters, either the saturated water content, $\theta_{s}$ or the saturated hydraulic con- 
ductivity, $K_{s}$, will enhance the likelihood of uniqueness and stability of the inverse solution in the estimation process. Using available collected data, we cannot prove the uniqueness of our estimated parameters without including $\theta_{s}$ and $K_{s}$ as known parameters. Therefore, in a subsequent study we will be collecting additional data (especially pressure heads and water contents at different locations, as well as independently measured retention and hydraulic conductivity functions) to be able to better evaluate results of our inverse analysis. We also plan to include nonreactive chemicals in the infiltrated water to study the possibility of inverse modeling for additional estimation of solute transport properties.

\section{REFERENCES}

Bard, Y., 1974. Nonlinear parameter estimation. Academic Press, New York, NY.

Bohne, K., Roth, C., Leij, F.J., van Genuchten, M.T., 1992. Rapid method for estimating the unsaturated hydraulic conductivity from infiltration measurement. Soil Sci., 155, 4, 237-244.

Chung, S.O., Horton, R., 1987. Soil heat and water flow with a partial surface mulch. Water Resour. Res., 23, 12, 21752186.

Clausnitzer, V., Hopmans, J.W., 1995. Non-linear parameter estimation: LM_OPT. General-purpose optimization code based on the Levenberg-Marquardt algorithm. Land, Air and Water Resources Paper No. 100032, University of California, Davis, CA.

Constantz, J., 1982. Temperature dependence of unsaturated hydraulic conductivity of two soils. Soil Sci. Soc. Am. J., 46, 3, 466-470.

Dane, J.J., Topp, G.C., (Eds.), 2002. Methods of Soil Analysis. Part 4 - Physical Methods. Soil Sci. Soc. Am., Inc., Madison, WI.

de Marsily, G., 1986. Quantitative Hydrogeology. Academic Press, London.

de Vries, D.A., 1963. The thermal properties of soils. In: van Wijk, R.W. (Ed.): Physics of Plant Environment, North Holland, Amsterdam, pp. 210-235.

Dirksen, C., 1991. Unsaturated hydraulic conductivity. In: Smith, K.A., Mullins, C.E. (Eds.): Soil Analysis: Physical Methods. Marcel Dekker, Inc., New York, pp. 209-269.

Dirksen, C., 2000. Unsaturated hydraulic conductivity. In: Smith, K.A., Mullins, C.E. (Eds.): Soil Analysis: Physical Methods, second ed., Marcel Dekker Inc., New York, pp. 183-237.

Finsterle, S., Najita, J., 1998. Robust estimation of hydrologic model parameters. Water Resour. Res., 34, 2939-2947.

Hollenbeck, K., Šimůnek, J., van Genuchten, M.Th.., 2000. RETCML: Incorporating maximum-likelihood estimation principles in the hydraulic parameter estimation code RETC. Comput. Geosci., 26, 319-327.

Hopmans, J.W., Šimůnek, J., 1999. Review of inverse estimation of soil hydraulic properties. In: van Genuchten, M.Th., et al. (Ed.): Characterization and Measurement of the Hydraulic Properties of Unsaturated Porous Media. University of California, Riverside, California, pp. 643-659.

Hopmans, J.W., Šimůnek, J., Bristow, K.L., 2002. Indirect estimation of soil thermal properties and water flux from heat pulse measurements: Geometry and dispersion effects. Water Resour. Res., 38, 1, 7.1-7.14.

Inoue, M., Šimůnek, J., Shiozawa, S., Hopmans, J.W., 2000. Estimation of soil hydraulic and solute transport parameters from transient infiltration experiments. Adv. Water Resour., 23, 677-688.

Klute, A., (Ed.) 1986. Methods of Soil Analysis. Part 1, Second edition. Agronomy Monograph, 9, 635-662, ASA and SSSA, Madison, WI.,

Kool, J.B., Parker, J.C., 1987. Development and evaluation of closed-form expressions for hysteretic soil hydraulic properties. Water Resour. Res., 23, 1, 105-114.

Kool, J.B., Parker, J.C., van Genuchten, M.Th., 1987. Parameter estimation for unsaturated flow and transport models - A review. J. Hydrol., 91, 255-293.

Nassar, I.N., Horton, R., 1992. Simultaneous transfer of heat, water, and solute in porous media: I. Theoretical development. Soil Sci. Soc. Am. J., 56, 1350-1356.

Marquardt, D.W., 1963. An algorithm for least-squares estimation of nonlinear parameters. Journal of the Society of Industrial and Applied Mathematics, 11, 2, 431-441.

Mortensen, A.P., Hopmans, J.W., Mori, Y., Šimůnek, J., 2006. Multi-functional heat pulse probe measurements of coupled vadose zone flow and transport. Adv. Water Resour., 29, 2 , 250-267.

Mualem, Y., 1976. A new model for predicting the hydraulic conductivity of unsaturated porous media. Water Resour. Res., 12, 3, 513-522.

Philip, J.R., de Vries, D.A., 1957. Moisture movement in porous materials under temperature gradients. Trans. Am. Geophys. Union, 38, 222-232.

Radcliffe, D.E, Šimůnek, J., 2010. Soil Physics with HYDRUS. CRC Press, Taylor \& Francis Group, Boca Raton, FL, ISBN: 978-1-4200-7380-5, pp. 373.

Reynolds, W.D., Elrick, D.E., Youngs, E.G., 2002a. Ring or cylinder infiltrometers (vadose zone). In: Dane, J.H., Topp, G.C. (Eds.): Methods of Soil Analysis. Part 4 - Physical Methods. SSSA No. 5, Soil Science Society of America, Inc. Madison, Wisconsin, pp. 818-820.

Reynolds, W.D., Elrick, D.E., Youngs, E.G., 2002b. Singlering and double or concentric-ring infiltrometers. In: Dane, J., Topp, G.C. (Eds): Methods of Soil Analysis. Part 4 Physical Methods. SSSA No. 5, Soil Science Society of America, Inc. Madison, WI, pp. 821-826.

Russo, D., Shani, U., Parker, J.C., 1991. Analyses of infiltration, events in relation to determining soil hydraulic properties by inverse problem methodology. Water Resour. Res., 27, 1361-1373.

Saito, H., Šimůnek, J., Mohanty. B., 2006. Numerical analyses of coupled water, vapor and heat transport in the vadose zone. Vadose Zone J., 5, 2, 784-800.

Saito, H., Šimůnek, J., Hopmans, J.W., Tuli, A., 2007. Numerical evaluation of the heat pulse probe for simultaneous estimation of water fluxes and soil hydraulic and thermal properties. Water Resour. Res., 43, W07408.

Sakai, M., Toride, N., Šimůnek, J., 2009. Water and vapor movement with condensation and evaporation in a sandy column subject to temperature gradient. Soil Sci. Soc. Am. J., 73, 3, 707-717.

Schaap, M. G., Leij, F. J., van Genuchten, M. Th., 2001. Rosetta: A computer program for estimating soil hydraulic parameters with hierarchical pedotransfer functions. J. Hydrol., 251, 163-176.

Shepard, F. P., 1954. Nomenclature based on sand-silt-clay ratios. Journal of Sedimentary Petrology, 24, 151-158.

Šimůnek, J., Suarez, D.L., 1993. The UNSATCHEM-2D code for simulating two-dimensional variably saturated water flow, heat transport, carbon dioxide production and transport, and multicomponent solute transport with major 
ion equilibrium and kinetic chemistry. Version 1.1, Research Report No. 128, U. S. Salinity Laboratory, USDA, ARS, Riverside, California.

Šimůnek, J., van Genuchten, M.Th., 1996. Estimating unsaturated soil hydraulic properties from tension disc infiltrometer data by numerical inversion. Water Resour. Res., 32, 9, 2683-2696.

Šimůnek, J., Angulo-Jaramillo, R., Schaap, M., Vandervaere, J.P., van Genuchten, M.Th., 1998. Using an inverse method to estimate the hydraulic properties of crusted soils from tension disc infiltrometer data. Geoderma, 86, 1-2, 61-81.

Šimůnek, J., Jacques, D., Hopmans, J.W., Inoue, M., Flury, M., van Genuchten, M.Th., 2002. Solute Transport During Variably-Saturated Flow - Inverse Methods. In: Dane, J.H., Topp, G.C. (Eds.): Methods of Soil Analysis. Part 4 - Physical Methods. Third edition, Chapter 6.6, SSSA, Madison, Wisconsin, pp. 1435-1449.

Šimůnek, J., Šejna, M., van Genuchten, M.Th., 2006. The hydrus software package for simulating two- and threedimensional movement of water, heat, and multiple solutes in variably-saturated media. User Manual, Version 1.0, PC Progress, Prague, Czech Republic.
Šimůnek, J., van Genuchten, M.Th., Šejna, M., 2008. Development and applications of the HYDRUS and STANMOD software packages, and related codes. Vadose Zone J., 7, 2, 587-600.

Sophocleous, M., 1979. Analysis of water and heat flow in unsaturated-saturated porous media. Water Resour. Res., 15, $5,1195-1206$.

van Genuchten, M.Th., 1980. A closed-form equation for predicting the hydraulic conductivity of unsaturated soils. Soil Sci. Soc. Am. J., 44, 892-898.

Vogel, T., Císlerová, M., Hopmans, J.W., 1991. Porous media with linearly variable hydraulic properties. Water Resour. Res., 27, 10, 2735-2741.

Vrugt, J.A., Stauffer, P.H., Wöhling, T., Robinson, B.A., Vesselinov, V., 2008. Inverse modeling of subsurface flow and transport properties: A review with new developments. Vadose Zone J., 7, 2, 843-864.

Wooding, R.A., 1968. Steady infiltration from large shallow circular pond. Water Resour. Res., 4, 1259-1273.

Received 11 June 2013 Accepted 22 November 2013 